\title{
O polietilenoglicol aumenta a penetração do vírus da diarréia viral bovina, do vírus da estomatite vesicular e do vírus sincicial respiratório bovino em células de cultivo
}

\author{
Polyethylene glycol increases the penetration of bovine viral diarrhea virus, vesicular stomatitis virus \\ and bovine respiratory syncytial virus in cultured cells
}

\author{
Renata Dezengrini ${ }^{\text {I }}$ Juliana Felipetto CargneluttiI ${ }^{\text {II }}$ Rudi Weiblen ${ }^{\text {III }}$ Eduardo Furtado Flores ${ }^{\text {III* }}$
}

RESUMO

A baixa eficiência de penetração de alguns vírus em células de cultivo pode representar uma dificuldade para o isolamento e a multiplicação viral in vitro. No presente estudo investigou-se o efeito do polietilenoglicol (PEG) na replicação de sete vírus bovinos em células de linhagem de rim bovino (MDBK). A eficiência de penetração e replicação foi mensurada pela contagem do número de placas virais produzidas em tapetes celulares, após adsorção do inóculo viral (100 DICC $\mathrm{DL}_{50} \mathrm{~mL}^{-1}$ ) com ou sem a adição de PEG a 5\% (peso molecular 6.000). A adição de PEG ao inóculo resultou em aumentos significativos do número de placas para o vírus da diarréia viral bovina (BVDV) (aumento de 3,4 vezes), vírus da estomatite vesicular (VSV) (2,2 vezes) e vírus respiratório sincicial bovino (BRSV) (1,5 vezes). A adição de PEG não produziu aumento significativo no número de placas dos herpesvírus bovinos 1, 2 e 5 (BoHV-1, BoHV-2 e BoHV-5). Por outro lado, o PEG produziu uma redução do número de placas (1,4 vezes) produzidas pelo vírus da parainfluenza bovina (bPI3V). A adição de PEG a 5\% também aumentou a sensibilidade de detecção (entre 10 e 100 vezes) do BVDV no soro de três bezerros persistentemente infectados. Para o BRSV, a adição de PEG aumentou em duas vezes a sensibilidade do isolamento viral de secreções nasais de duas ovelhas infectadas experimentalmente. Esses resultados demonstram que o PEG aumenta a eficiência de infecção do BVDV, VSV e BRSV em células de cultivo, podendo ser utilizado para aumentar a sensibilidade de deteç̧ão desses vírus em amostras clínicas (isolamento viral) elou, para aumentar os títulos de vírus produzidos em cultivo celular.

Palavras-chave: polietilenoglicol, PEG, VSV, BVDV, BRSV, bPI-3V, penetração viral.

\begin{abstract}
The low efficiency of penetration of some viruses in cultured cells may represent an obstacle for viral isolation and/or viral multiplication in tissue culture. This study investigated the effect of polyethylene glycol (PEG) on the penetration and replication of seven bovine enveloped viruses in culture cells. Penetration efficiency was measured by counting the number of viral plaques produced in bovine kidney cells (MDBK). The addition of 5\% PEG (molecular weight 6.000) to the viral inoculum containing $100 \mathrm{TCID}_{50} \mathrm{~mL}^{-1}$ (tissue culture median infectious dosis) of each virus, during adsorption for $2 \mathrm{~h}$ at $37^{\circ} \mathrm{C}$, resulted in a significant increase in the number of plaques for bovine viral diarrhea virus (BVDV) (increase of 3.4-fold), vesicular stomatitis virus (VSV) (2.2-fold) and bovine respiratory syncytial virus (BRSV) (1.5-fold). The addition of 5\% PEG to the inoculum of bovine herpesviruses 1, 2 and 5 (BoHV-1, BoHV-2 and BoHV-5) did not increase the number of viral plaques. On the other hand, PEG produced a reduction in the number of plaques by bovine parainfluenza virus (bPI3V) (1.4-fold). Furthermore, the addition of 5\% PEG produced a 10- to 1000-fold increase in the sensitivity of BVDV detection in the serum of three persistently infected calves; and doubled the sensitivity of detection of BRSV in nasal secretions of two experimentally infected sheep. These results demonstrate that PEG enhances the efficiency of infection by BVDV, VSV and $B R S V$ in cultured bovine cells and therefore may be used to increase the sensitivity of virus detection in clinical samples (viral isolation), and/or to increase virus titers in cell cultures.
\end{abstract}

Key words: polyethylene glycol, PEG, VSV, BVDV, BRSV, bPI$3 \mathrm{~V}$, viral penetration.

IPrograma de Pós-graduação em Medicina Veterinária, Universidade Federal de Santa Maria (UFSM), Santa Maria, RS, Brasil. "Curso de Medicina Veterinária, UFSM, Santa Maria, RS, Brasil.

IIISetor de Virologia, Departamento de Medicina Veterinária Preventiva (DMVP), Centro de Ciências Rurais (CCR), UFSM, Santa Maria, RS, Brasil. E-mail: flores@ccr.ufsm.br. *Autor para correspondência 


\section{INTRODUÇÃO}

A penetração de vírus envelopados nas células hospedeiras envolve as etapas de ligação de proteínas virais de superfície a receptores celulares e, em seguida, a penetração por fusão do envelope com a membrana plasmática. A penetração por fusão pode ocorrer na superfície celular (processo independente de $\mathrm{pH}$ ) ou no interior de vesículas, após endocitose (processo pH dependente) (ROIZMAN \& PALESE, 1996). As fases iniciais de infecção - ligação aos receptores e fusão/penetração - se constituem em etapas críticas na replicação de vários vírus em cultivo celular e a baixa eficiência desses processos pode comprometer tentativas de isolamento viral de amostras clínicas e a obtenção de títulos virais altos (MARSH \& HELENIUS, 1989; CHOU, 2007). Procedimentos como a adição de dietilaminoetil-dextran (DEAE-D), forbol 12-miristato 13-acetato, tratamento prévio com tripsina, temperatura de incubação reduzida, aquecimento das células, e inoculação de células de cultivo sob centrifugação têm sido empregados para aumentar a eficiência de penetração e, conseqüentemente, de replicação de vírus humanos e animais em cultivos celulares (ROSSI \& KIESEL, 1978; SARMANTI et al., 1994; FLORES \& DONIS, 1995; ARIAS et al., 1996; FLORES, E.F. comunicação pessoal).

O polietilenoglicol (PEG) é um agente desidratante que favorece o contato e a interação entre lipídeos, propiciando o desenvolvimento de um ambiente hidrofóbico e, conseqüentemente, a fusão de membranas lipídicas (HOEKSTRA et al., 1989). Esse polímero tem sido utilizado com diversos propósitos em virologia, como a investigação de bases biológicas de resistência de células à infecção viral (ASANAKA \& LAI, 1993; FLORES \& DONIS, 1995; FLORES et al., 1996; DEZENGRINI et al., 2006) e a identificação de glicoproteínas e receptores responsáveis pela penetração de vírus nas células-alvo (SUBRAMANIAN et al., 1995; KARGER et al., 1998). Acredita-se que o PEG medeie a infecção viral de células de cultivo por duas vias principais: aumentando ou estabilizando a ligação do vírus aos receptores (HOEKSTRA et al., 1989) ou favorecendo a fusão entre as membranas viral (envelope) e celular (HOEKSTRA et al., 1989; ASANAKA \& LAI, 1993).

Os herpesvírus, dentre os quais os herpesvírus bovinos tipos 1, 2 e 5 (BoHV-1, BoHV-2, BoHV-5), penetram nas células hospedeiras após fusão do envelope com a membrana plasmática, mecanismo que ocorre na superfície celular e independe de $\mathrm{pH}$ baixo (SHIEH \& SPEAR, 1994). O vírus da estomatite vesicular (VSV), um Vesivirus da família
Rhabdoviridae, penetra por meio de fusão com a membrana endocítica, após endocitose (MARSH \& HELENIUS, 1989). O mecanismo de penetração do BVDV - um pestivírus da família Flaviviridae - envolve fusão do envelope com a membrana endocítica, sob pH levemente acidificado (LECOT et al., 2005). O BRSV (gênero Pneumovirus) e o bPI-3V (gênero Respirovirus) são membros da família Paramyxoviridae e penetram nas células hospedeiras por fusão do envelope viral com a membrana plasmática, evento que ocorre na superfície celular, sob pH neutro (LAMB et al., 2006). Esses vírus são importantes patógenos de bovinos e, consequentemente, são frequentemente pesquisados em amostras clínicas com finalidades diagnósticas. Também são manipulados com grande freqüência em laboratórios envolvidos em diagnóstico, pesquisa e produção de vacinas na área de virologia animal.

O objetivo deste estudo foi investigar a ação do PEG na penetração desses vírus bovinos em cultivo de células. $\mathrm{O}$ efeito do PEG foi avaliado pela contagem e comparação do número de placas virais produzidas em tapetes de células de linhagem de rim bovino (MDBK), a linhagem celular mais utilizada para a multiplicação de vírus bovinos.

\section{MATERIAL E MÉTODOS}

Células e vírus

Os procedimentos de amplificação, quantificação de vírus, ensaios de citotoxicidade e ensaios de placa foram realizados em células de linhagem de rim bovino MDBK (ATCC, CCL-22) cultivadas em meio essencial mínimo (MEM) suplementado com $5 \%$ de soro eqüino (SE), estreptomicina $\left(0,4 \mathrm{mg} \mathrm{mL}^{-1}\right)$, penicilina $\left(1,6 \mathrm{mg} \mathrm{mL}^{-1}\right)$, nistatina $\left(0,002 \mathrm{mg} \mathrm{mL}^{-1}\right)$ e fungizona $\left(0,0025 \mathrm{mg} \mathrm{mL}^{-1}\right)$. Foram utilizadas as seguintes amostras/cepas virais: BoHV-1 SV56/90, BoHV-5 SV-507 (isoladas no SV/ UFSM); BoHV-2, VSV, BRSV (cepas cedidas pelo Dr. Fernando Osório, University of Nebraska at Lincoln [UNL], Nebraska [NE], EUA); BVDV Singer (cedida pelo Dr. Ruben Donis, UNL) e bPI-3V (MEDEIROS et al., 2002). Os experimentos in vitro com o VSV foram realizados no laboratório do Dr. Ruben Donis, UNL, NE, USA.

\section{Teste de citotoxicidade - MTT}

Previamente aos ensaios com os vírus, foram realizados testes de citotoxicidade (teste de MTT, Thiazolyl Blue Tetrazolium Bromide), avaliando-se a viabilidade de uma quantidade constante de células $\operatorname{MDBK}\left(1,6 \times 10^{5}\right.$ por cavidade da placa de 96 poços) 
frente a diferentes concentrações de PEG (PM 6.000) ${ }^{\mathrm{a}}$ em triplicata. Foram testadas concentrações crescentes de PEG $(0,1,5,10,15,20,25$ e 50\%) adicionadas ao meio de cultivo e incubadas durante $24 \mathrm{~h}$. Em seguida, as células foram incubadas com $\mathrm{MTT}^{\mathrm{b}}\left(1 \mathrm{mg} \mathrm{mL}^{-1}\right) \mathrm{em}$ meio de cultivo por duas horas e com $200 \mu \mathrm{L}$ de dimetilsulfóxido (DMSO) por 15min. A absorbância (OD) foi medida a um comprimento de onda de $570 \mathrm{~nm}$, filtro de $620 \mathrm{~nm}$, em leitor de ELISA. Esse teste foi realizado em duas repetições independentes, de acordo com GARRÉ et al. (2007). A viabilidade de células foi calculada pela seguinte fórmula: \% células viáveis = média OD ([]PEG) x 100/média OD (controle celular). A concentração de 5\% de PEG foi escolhida para os ensaios com os vírus, pois situou-se abaixo da concentração citotóxica.

Quantificação do número de placas virais

A quantificação do número de placas virais produzidas em tapetes celulares, na presença e ausência de PEG a 5\%, foi realizada pelo uso de ensaios de placa (MAHY \& KANGRO, 1996). Para tal, monocamadas confluentes de células MDBK cultivadas em placas de seis cavidades foram incubadas $\left(2 \mathrm{~h}\right.$ a $\left.37^{\circ} \mathrm{C}\right)$, com uma suspensão viral (sobrenadante de cultivos celulares) contendo aproximadamente $100 \mathrm{DICC}_{50}$ (doses infectantes para $50 \%$ dos cultivos celulares) de cada vírus, sendo adicionados de 5\% PEG (tratado) ou igual volume de MEM (controles). Após duas horas de incubação, os inóculos foram removidos, os tapetes foram lavados com MEM e adicionados de $2 \mathrm{~mL}$ de MEM contendo $5 \%$ de SE e $0,95 \%$ de carboximetilcelulose. Após 48-72h, foi contado o número de placas virais produzidas nos tapetes celulares. Assim, calculou-se o número médio de placas virais produzidas nos tapetes inoculados com o vírus na presença (tratados) e ausência de PEG a 5\%. Os testes foram realizados em duplicata, com cinco repetições cada (total de 10 cavidades com PEG e 10 controles para cada vírus). A comparação entre as médias foi realizada por análise de variância (ANOVA), usando o programa SPSS. A análise post hoc foi realizada pela aplicação do teste Duncan. $\mathrm{P}<0,05$ foi considerado significativo.

Isolamento de vírus de amostras clínicas

Um segundo experimento foi realizado para se investigar a ação do PEG no isolamento de dois vírus (BVDV e BRSV) a partir de amostras clínicas. Para o BVDV, foram utilizadas amostras de soro de três animais persistentemente infectados, PI com o vírus. As amostras de soro foram diluídas em MEM na base 10 , e as diferentes diluições $\left(10^{-1}\right.$ a $\left.10^{-6}\right)$ foram divididas em duas alíquotas: uma alíquota foi misturada com um volume equivalente de uma solução de PEG a $10 \%$ (concentração final de PEG de 5\%), e a outra alíquota foi misturada com igual volume de MEM. Para o BRSV, foram utilizadas secreções nasais coletadas de dois ovinos infectados experimentalmente. Foram utilizadas secreções coletadas no dia 2 pós-infecção, diluídas em MEM na base 2 (1:2 a 1:128), divididas em duas alíquotas e adicionadas de igual volume de solução de PEG a 10\% (tratado) ou MEM (controles). As suspensões virais (soro de animais PI [BVDV]; secreções nasais de ovinos [BRSV]) com e sem PEG, em diferentes diluições, foram inoculadas em tapetes de células MDBK (cultivadas em placas de 24 cavidades) e deixadas em adsorção por duas horas. Em seguida, o inóculo foi removido, e os tapetes foram adicionados de meio de cultivo. A replicação viral foi monitorada pela realização de imunofluorescência para antígenos do BVDV (BOTTON et al., 1998) ou BRSV (FLORES et al., 2000) nos cultivos celulares, 96h após a inoculação viral. Assim, pode-se comparar a sensibilidade de detecção viral nas amostras tratadas e não-tratadas com PEG durante a adsorção.

\section{RESULTADOS E DISCUSSÃO}

O teste de viabilidade pelo MTT revelou que concentrações de PEG iguais ou superiores a 15\%, após incubação por $24 \mathrm{~h}$, resultam em toxicidade para as células MDBK, reduzindo a viabilidade celular para $37,9 \%$ (Tabela 1). Assim, a concentração de 5\% foi utilizada nos ensaios com os vírus. Nessa concentração, a viabilidade após $24 \mathrm{~h}$ permaneceu próxima de $85 \%$. Essa mesma concentração de PEG já havia sido utilizada em experimentos destinados a aumentar a eficiência de penetração do BVDV em células resistentes à infecção natural (FLORES \& DONIS, 1995; FLORES et al., 1996; DEZENGRINI et al., 2006).

Os resultados dos ensaios de placa, nos quais se avaliou o efeito do PEG a 5\% na penetração mensurada pela formação de placas ou focos infecciosos - dos respectivos vírus em células MDBK estão apresentados na figura 1. A adição de PEG ao inóculo durante a adsorção viral aos cultivos resultou em aumentos significativos $(\mathrm{P}<0,05)$ no número de placas para o BVDV ( 3,4 vezes), VSV (2,2 vezes) e BRSV ( 1,5 vezes). Não houve diferença significativa $(\mathrm{P}>0,05)$ no número de placas produzidas pelos herpesvírus (BoHV-1, 2 e 5) e, curiosamente, o tratamento do inóculo com $\mathrm{PEG}$ reduziu o número de placas produzidas pelo bPI-3v (Figura 1).

$\mathrm{O}$ efeito do $\mathrm{PEG}$ sobre a penetração do BVDV - e também de outros pestivírus - em células de 
Tabela 1 - Viabilidade de células de linhagem de rim bovino (MDBK) incubadas por 24h com diferentes concentrações de polietilenoglicol (PEG) pelo teste de MTT (Thiazolyl Blue Tetrazolium Bromide).

\begin{tabular}{lcccccc}
\hline \multirow{2}{*}{ MTT } & - & & & \\
& $0-1$ & 5 & 10 & 15 & 20 & 25 \\
\hline Viabilidade celular $(\%)^{1}$ & $100^{2}$ & 84,4 & 81,9 & 37,9 & 17,4 & 6,4 \\
\hline
\end{tabular}

${ }^{1}$ Teste realizado com $1,6 \times 10^{5}$ células MDBK por cavidade, em comparação com células incubadas sem PEG. Os testes foram conduzidos em triplicata, em duas repetições independentes. Os valores apresentados representam as médias obtidas nesses experimentos e nessas repetições.

${ }^{2}$ Foram consideradas tóxicas para células MDBK as concentrações de PEG que resultaram em viabilidade celular inferior a $80 \%$.

cultivo defectivas em funções envolvidas nos estágios iniciais da infecção viral já havia sido demonstrado anteriormente (FLORES et al., 1996; DEZENGRINI et al., 2006). Em uma linhagem mutante de células MDBK resistente à infecção natural pelo BVDV (células CRIB), a adição de $P E G$ resultou em um aumento de 1000 vezes na eficiência de penetração do vírus (FLORES \& DONIS, 1995). Em outras linhagens celulares, também defectivas em funções envolvidas na penetração do BVDV, o PEG apresentou efeitos semelhantes, aumentando significativamente a penetração e replicação do vírus. A adição de PEG resultou em um aumento superior a 437, 346 e 87 vezes na eficiência de penetração do BVDV em células resistentes das linhagens de origem canina, suína e leporina (MDCKR, PK-15-R e RK-13R, respectivamente; DEZENGRINI et al., 2006). Embora o mecanismo exato de ação não seja conhecido, acredita-se que o PEG favoreça as interações iniciais dos vírions com moléculas da superfície celular, resultando em maior eficiência de internalização dos mesmos (FLORES et al., 1996).

Por outro lado, o efeito do PEG sobre a eficiência de replicação do VSV e BRSV não havia sido investigado anteriormente. O BRSV é um vírus de difícil isolamento e replicação em cultivo celular, em parte devido a problemas de conservação das amostras clínicas. De fato, a dificuldade de isolamento e multiplicação do BRSV em cultivo tem motivado o uso de diferentes protocolos com o objetivo de aumentar a eficiência de replicação (SPILKI et al., 2006). Dentre estes, estão incluídas a utilização de células de diferentes tecidos e/ou espécies animais, a substituição do inóculo viral após algum tempo de adsorção, a adição de DEAE-D ao inóculo e a incubação dos cultivos a $33^{\circ} \mathrm{C}$ (ROSSI \& KIESEL, 1978; SPILKI et al., 2006; FLORES, E.F. dados não publicados). Pelos resultados obtidos no presente estudo, a adição de PEG 5\% resultou em um aumento de 1,5 vezes no número de placas produzidas pelo BRSV em cultivo celular. Além disso, o vírus foi detectado em diluições duas vezes maiores em secreções nasais adicionadas de PEG 5\%. Assim, tanto para o BVDV, quanto para o BRSV, a adição de PEG ao inóculo pode ser útil em procedimentos de isolamento e amplificação viral em laboratório com finalidades diversas. Esse protocolo pode ser particularmente útil para o BRSV, pelas dificuldades de ser isolado a partir de amostras clínicas. A adição de PEG a 5\% ao inóculo durante a adsorção, associado ou não com os outros procedimentos descritos por SPILKI et al. (2006), pode também contribuir para a obtenção de títulos virais mais altos, necessários para vários procedimentos laboratoriais. No caso do BVDV e VSV, esse protocolo pode também auxiliar na obtenção de títulos virais mais altos, embora esses vírus geralmente repliquem a títulos altos, independentemente de tratamentos para aumentar a eficiência de penetração/replicação. O mecanismo de ação do PEG sobre o VSV e BRSV também é desconhecido, mas é possível que seja semelhante ao observado com o BVDV, visto que os mecanismos de penetração desses vírus nas células apresentam similaridades (MARSH \& HELENIUS, 1989; LECOT et al., 2005; LAMB et al., 2006).

A falha do PEG em aumentar a eficiência de penetração dos herpesvírus e do bPI-3V nas células de cultivo (Figura 1) provavelmente deve-se a mecanismos e/ou interações peculiares que medeiam a penetração desses vírus nas células hospedeiras. Interessantemente, com relação ao bPI-3V, houve uma redução no número de placas produzidas nos cultivos inoculados na presença de PEG. É provável que o polímero atue sobre as partículas víricas e/ou sobre componentes da membrana celular, afetando negativamente as interações que eventualmente resultam em fusão e penetração viral.

Uma das possíveis aplicações do protocolo descrito anteriormente seria o aumento da sensibilidade do isolamento de vírus a partir de amostras clínicas. Nesses casos, a quantidade de partículas infecciosas é frequentemente pequena, o que pode dificultar a sua 


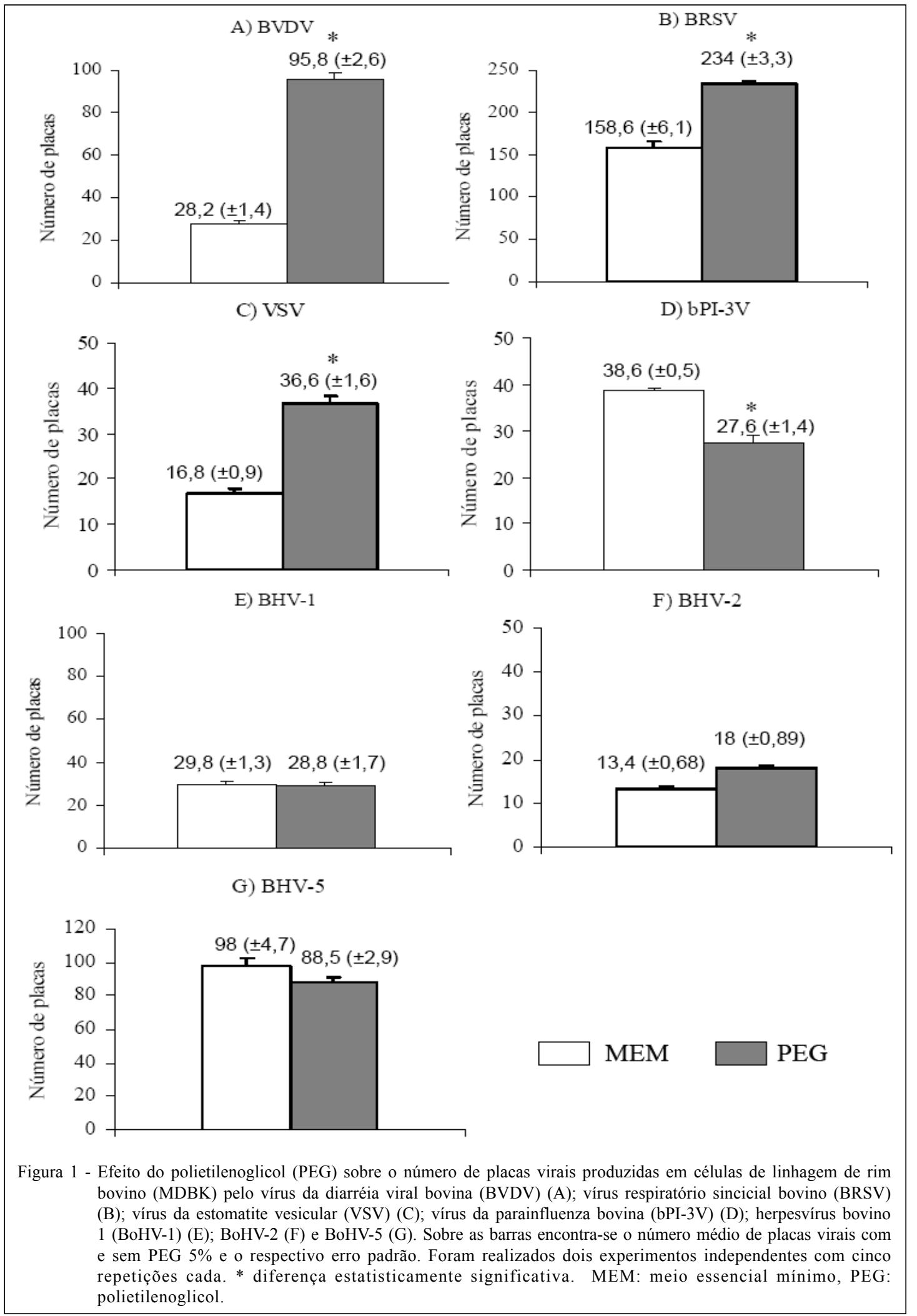

Ciência Rural, v.39, n.3, mai-jun, 2009. 
detecção e resultar em resultados falso-negativos (FLORES, 2007). Embora seja comum a vários vírus, incluindo o BVDV, esse problema é particularmente crítico para o BRSV, cujo isolamento de amostras clínicas é ainda mais dificultado pela labilidade dos vírions sob condições ambientais (LARSEN, 2000; SPILKI et al., 2006). Assim, utilizou-se o mesmo protocolo para investigar se a adição de PEG aumentaria a sensibilidade de detecção do BVDV e BRSV em amostras clínicas. Para o BVDV, foram utilizadas amostras de soro de três bezerros persistentemente infectados (PI). Para o BRSV, foram utilizadas secreções nasais de dois ovinos inoculados experimentalmente, com esse propósito. Nas amostras de soro dos animais PI, a adição de PEG ao inóculo resultou na detecção de vírus em diluições entre 10 e 1000 vezes maiores, comparando-se com a detecção do vírus em diluições não tratadas (Tabela 2). Os experimentos foram repetidos três vezes, com as mesmas amostras, e os resultados foram consistentes e repetidos. A explicação para a variação dos níveis de aumento na sensibilidade (10 a 1000 vezes) observado no soro dos animais pode ser a diferente quantidade de partículas víricas presentes nas amostras. Na presença de altos títulos virais, o aumento da sensibilidade provavelmente seja maior do que em amostras que contêm pequena quantidade de vírus.

Nas amostras de secreções nasais coletadas de ovinos infectados com o BRSV, foi possível detectar antígenos virais em cultivos inoculados com PEG em diluições duas vezes maiores do que em cultivos inoculados sem PEG (Tabela 2). A exemplo dos testes realizados com o sobrenadante de cultivos celulares, o efeito do PEG foi mais pronunciado sobre o BVDV do que sobre o BRSV. Essa diferença provavelmente reflete peculiaridades nas interações iniciais desses vírus com as células hospedeiras, as quais seriam influenciadas em níveis diferentes pelo PEG. Esses resultados demonstram que, a exemplo do que foi observado com o sobrenadante de cultivos celulares, a inoculação de amostras clínicas com 5\% PEG aumenta a sensibilidade de detecção do BVDV e BRSV em células MDBK.

O PEG tem sido utilizado como ferramenta em virologia para elucidar os mecanismos e as glicoproteínas virais envolvidas nas interações dos vírions do herpes simplex humano (SUBRAMANIAN et al., 1995), vírus da pseudoraiva (KARGER et al., 1998) e BVDV (FLORES et al., 1996) com a membrana das células. Além disso, a indução da fusão do envelope com a membrana de células pelo PEG também tem sido utilizada para verificar a permissividade intracelular de diferentes linhagens celulares aos vírus da hepatite murina (ASANAKA \& LAI, 1993) e do BVDV (FLORES \& DONIS, 1995; DEZENGRINI et al., 2006). O PEG também tem se mostrado uma excelente alternativa para a amplificação e detecção de vírus em amostras clínicas. A adição de PEG 4\% ao inóculo do vírus Sendai aumentou em cinco vezes a eficiência de fusão do envelope viral com a membrana de eritrócitos, mediada pela hemaglutinina/neuraminidase (HOEKSTRA et al., 1989). A adição de PEG a amostras de soro de pacientes com infecção crônica pelo vírus da hepatite $\mathrm{B}$ aumenta a detecção de DNA em cultivos primários de hepatócitos (GRIPON et al., 1993). A adição de PEG também aumentou significativamente o isolamento do vírus da imunodeficiência humana (HIV) a partir do sangue de pacientes assintomáticos (SARMANTI et al., 1994).

Assim, os resultados do presente estudo estendem as observações prévias da ação favorável

Tabela 2 - Efeito do polietilenoglicol (PEG) a 5\% sobre a detecção do vírus da diarréia viral bovina (BVDV) e vírus respiratório sincicial bovino (BRSV) no sobrenadante de cultivos celulares infectados e em amostras clínicas.

\begin{tabular}{|c|c|c|c|}
\hline \multirow{2}{*}{ Origem do vírus (título em $\mathrm{DICC}_{50} \mathrm{ml}^{-1}$ ) } & \multicolumn{2}{|c|}{ Maior diluição positiva no isolamento ${ }^{\mathrm{a}}$} & \multirow{2}{*}{$\begin{array}{c}\text { Aumento na sensibilidade de detecção } \\
\text { de vírus (vezes) }{ }^{\mathrm{b}}\end{array}$} \\
\hline & Controle & PEG 5\% & \\
\hline BVDV Singer (sobrenadante de cultivo, $10^{5,4}$ ) & $10^{-3}$ & $10^{-6}$ & 1000 \\
\hline Soro terneiro PI \# $1\left(10^{4,8}\right)$ & $10^{-3}$ & $10^{-5}$ & 100 \\
\hline Soro terneiro PI \# $2\left(<10^{1,8}\right)$ & $10^{-1}$ & $10^{-2}$ & 10 \\
\hline Soro terneiro PI \# $3\left(10^{4,8}\right)$ & $10^{-3}$ & $10^{-6}$ & 1000 \\
\hline BRSV (sobrenadante de cultivo, $10^{5,5}$ ) & $10^{-4}$ & $10^{-5}$ & 10 \\
\hline Secreção nasal ovelha \# $1\left(<10^{1,8}\right)$ & $1: 16$ & $1: 32$ & 2 \\
\hline Secreção nasal ovelha \# $2\left(<10^{1,8}\right)$ & $1: 8$ & $1: 16$ & 2 \\
\hline
\end{tabular}

${ }^{a} \mathrm{O}$ resultado do isolamento viral foi obtido pela realização de imunofluorescência (IFI) para antígenos virais nas células de cultivo, 96h após a inoculação viral.

b O aumento da sensibilidade foi calculado dividindo-se a maior diluição do inóculo com PEG na qual o vírus foi detectado pela maior diluição sem PEG na qual o vírus foi detectado. 
do PEG sobre o processo de penetração de alguns vírus em cultivos celulares. $\mathrm{O}$ estudo demonstrou que a adição de 5\% PEG ao inóculo viral durante a adsorção aumentou a eficiência de penetração e replicação do BVDV, VSV e BRSV em células MDBK. Esse aumento também foi demonstrado no isolamento viral a partir de amostras clínicas para o BVDV e BRSV. Como o PEG a $5 \%$ não é tóxico para as células, pode ser utilizado na rotina laboratorial para aumentar a eficiência de isolamento e/ou multiplicação desses vírus em cultivo celular. Esse protocolo pode ser também testado e eventualmente estendido a outros vírus animais que apresentam problemas para isolamento e/ou replicação eficiente em cultivo. Pode ser também testado em outras linhagens celulares e em cultivos primários, que são freqüentemente utilizados para isolamento viral.

\section{FONTESDEAQUISIÇÃO}

a-LabSynth LTDA, Diadema, SP.

b-Sigma-Aldrich, St Louis, MO, USA.

\section{REFERÊNCIAS}

ARIAS, C.F. et al. Trypsin activation pathway of rotavirus infectivity. Journal of Virology, v.70, n.9, p.5832-5839, 1996.

ASANAKA, M.; LAI, M.M.C. Cell fusion studies identified multiple cellular factors involved in mouse hepatitis vírus entry. Virology, v.197, p.732-741, 1993. Disponível em: http://www.sciencedirect.com/ science?_ob=ArticleURL\&_udi=B6WXR-45P694BW\& user $=687358 \&$ rdoc $=1 \& \mathrm{fm} t=\&$ orig $=$ search $\&$ sort $=\mathrm{d} \&$ vie $\mathrm{w}=\mathrm{c} \&$ _acct $=\mathrm{C} 000037899 \&$ \&ersion $=1 \&$ urlVersion $=0 \& \_$userid $=687358 \& \mathrm{md} 5=365 \mathrm{e} 6101 \mathrm{~b} 3248 \mathrm{bd} 4 \mathrm{e} 9664195 \mathrm{f} 3 \mathrm{c} 5 \mathrm{a} 511$. Doi: $10.1006 /$ viro.1993.1649.

BOTTON, S.A. et al. Antigenic characterization of Brazilian bovine viral diarrhea virus (BVDV) isolates by monoclonal antibodies and cross-neutralization. Brazilian Journal of Medical and Biological Research, v.31, n.11, p.1429-1438, 1998.

CHOU, T. Stochastic entry of enveloped viruses: fusion versus endocytosis. Biophysical Journal, v.93, n.4, p.1116-1123, 2007. Dispónível em: http://www.biophysj.org/cgi/content/ abstract/93/4/1116. Doi: 10.1529/biophysj.107.106708.

DEZENGRINI, R. et al. Selection and characterization of canine, swine and rabbit cell lines resistant to bovine viral diarrhea virus. Journal of Virological Methods, v.137, p.5157, 2006. Disponível em: http://www.sciencedirect.com/ science? ob=ArticleURL\& udi=B6T96-4KF7814$2 \& \_$user $=687358 \& \_$rdoc $=1 \& \_\mathrm{fmt}=$ \&_orig $=$ search\&_sort $=\mathrm{d} \&$ vie $\mathrm{w}=\mathrm{c} \&$ a c c t $=\mathrm{C} 000037899 \& \quad$ version $=1 \&$ u r 1 Ve r s i o n $=0$ \& u s e ri d $=687358 \&$ md5=dd9ee24a4fbf109aab5427147ea0c371. Doi: $10.1016 /$ j.jviromet.2006.05.032.

FLORES, E.F. Diagnóstico laboratorial das infecções víricas. In: FLORES, E.F. (Org). Virologia veterinária. Santa Maria: UFSM, 2007. p.295-326.
FLORES, E.F.; DONIS, R.O. Isolation of a mutant MDBK cell line resistant to bovine viral diarrhea virus (BVDV) infection due to a block in viral entry. Virology, v.208, p.565-575, 1995.

FLORES, E.F. et al. Swine and ruminant pestiviruses require the same cellular factor to enter bovine cells. Journal of General Virology, v.77, p.1295-1303, 1996. Disponível em: http://vir.sgmjournals.org/cgi/content/abstract/77/6/1295. Doi: 10.1099/0022-1317-77-6-1295.

FLORES, E.F. et al. A retrospective search for bovine respiratory syncytial virus (BRSV) antigens in histological specimens by immunofluorescence and immunohistochemistry. Pesquisa Veterinária Brasileira, v.20, p.139-143, 2000. Disponível em: http://www.scielo.br/scielo.php?script=sci_arttext\&pid=S0100$736 X 2000000400002 \&$ tlng=en\&lng $=$ en\&nrm=iso. Doi: $10.1590 /$ S0100-736X2000000400002.

GARRÉ, B. et al. In vitro susceptibility of six isolates of equine herpesvirus 1 to acyclovir, ganciclovir, cidofovir, adefovir, PMEDAP and foscarnet. Veterinary Microbiology, v.122, p.43-51, 2007. Disponível em: http://www.sciencedirect.com/ science? ob=ArticleURL\& udi=B6TD6-4MTK 95B$1 \& \_$user $=687358 \& \_$rdoc $=1 \& \_$fmt $=\& \_$orig $=$search \&_sort $=\mathrm{d} \&$ view $=\mathrm{c} \&$. acct $=\mathrm{C} 000037899 \&$ version $=1 \&$ urlVersion $=0 \&$ us erid $=687358 \& \mathrm{md} 5=1 \mathrm{ebe} 7 \mathrm{a} 4 \mathrm{ecb} 078688 \mathrm{c} 47 \mathrm{ffd} 5106 \mathrm{e} 9 \mathrm{~d} 177$. Doi: 10.1016/j.vetmic.2007.01.004.

GRIPON, P. et al. Reproducible high level infection of cultured adult human hepatocytes by hepatitis B virus: effect of polyethylene glycol on adsorption and penetration. Virology, v.192, p.534-540, 1993. Disponível em: http:// w w w. s c i e n c e d i r e c t . c o m / science? ob=ArticleURL\& udi=B6WXR-45PTMW4$8 R \& \_u s e r=687358 \& \_$rdoc $=1 \&$ fmt $=$ \&_orig $=$ search \&_sort $=$ d \& view $=\mathrm{c} \&$ acct $=\mathrm{C} 000037899 \&$ \&ersion $=1 \&$ ur 1 Version $=$ $0 \&$ userid $=687358 \& \mathrm{md} 5=4 \mathrm{a} 9 \mathrm{e} 8 \mathrm{e}$ bad151b7a3d8aa6370cf69ce 42 . Doi: $10.1006 /$ viro.1993.1069.

HOEKSTRA, D. et al. Mechanism of fusion of Sendai virus: role of hydrophobic interactions and mobility constrains of viral membrane proteins. Effect of polyethylene glycol. Journal of Biological Chemistry, v.264, n.12, p.6786-6792, 1989.

KARGER, A. et al. Infectivity of a pseudorabies virus mutant lacking attachment glycoproteins $\mathrm{C}$ and D. Journal of Virology, v.72, n.9, p.7341-7348, 1998.

LAMB, R.A. et al. Paramyxovirus membrane fusion: lessons from the $\mathrm{F}$ and $\mathrm{HN}$ atomic structures. Virology, v.344, n.1, p.30-37, 2006. Disponível em: http://www.sciencedirect.com/ science? ob=ArticleURL\& udi=B6WXR-4HTPV $1 \mathrm{~J}$ $6 \&$ _user $=687358 \&$ \& rdoc $=1 \&$ fmt $=\&$ orig $=$ search\&_sort $=\mathrm{d} \&$ vie $\mathrm{w}=\mathrm{c} \& \quad \mathrm{a} \mathrm{c} \mathrm{ct}=\mathrm{C} 000037899 \& \quad$ ver si o $=1 \&$ u r l Version $=0 \&$ \& s e rid $=687358 \& \mathrm{~m}$ $\overline{\mathrm{d}} 5=\mathrm{dff} 5 \mathrm{feb} 807 \mathrm{c} 7959 \mathrm{fcc} 400 \mathrm{~d} 6 \mathrm{ef} 6814 \mathrm{eb} 8$. Doi: $10.1016 /$ j.virol.2005.09.007.

LARSEN, L.E. Bovine respiratory syncytial virus (BRSV): a review. Acta Veteterinaria Scandinavica, v.41, p.1-24, 2000.

LECOT, S. et al. Bovine viral diarrhea virus entry is dependent on clathrin-mediated endocytosis. Journal of Virology, v.79, n.16, 10826-10829, 2005. Disponível em: http:// 
jvi.asm.org/cgi/content/abstract/79/16/10826. Doi: 10.1128/ JVI.79.16.10826-10829.2005.

MARSH, M.; HELENIUS, A. Virus entry into animal cells. Advances in Virus Research, v.36, p.107-151, 1989.

MAHY, B.W.; KANGRO, H.O. Virology methods manual. San Diego, CA: Academic, 1996. 374p.

MEDEIROS, M. et al. Caracterização preliminar de um paramixovírus contaminante de cultivos celulares. Acta Scientiae Veterinariae, v.30, n.1, p.43-52, 2002.

ROIZMAN, B.; PALESE, P. Multiplication of viruses: an overview. In: FIELDS, B. et al. Fields virology. 3.ed. Philadelphia: Lippincott Williams \& Wilkins, 1996. Cap.4, p.101-111.

ROSSI, C.R.; KIESEL, G.K. Bovine respiratory syncytial virus infection of bovine embryonic lung cultures: enhancement of infectivity with diethylaminoethyl-dextran and virus-infected cells. Archives of Virology, v.56, n.3, p.227-236, 1978. Disponível em: http://www.springerlink.com/content/11441354h34152n2/. Doi: $10.1007 /$ BF01317851.
SARMANTI, L. et al. High rate of HIV isolation from plasma of asymptomatic patients through polyethylene glycol (PEG) treatment. Journal of Acquired Immune Deficiency Syndrome, v.7, n.1, p.10-14, 1994.

SPILKI, F et al. Susceptibility of different cell lines to infection with bovine respiratory syncytial virus. Journal of Virological Methods, v.131, p.130-133, 2006. Disponível em: http://www.sciencedirect.com/ science?_ob=ArticleURL\&_udi=B6T96-4H5MYC5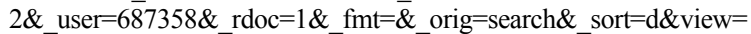 c \&_acct $=$ C000037899\&_version $=1 \&$ \& urlVersion $=0 \&$ userid $=687358 \& \mathrm{md} 5=465 \mathrm{fcb} 2 \mathrm{ffd} 5 \mathrm{e} 567 \mathrm{ee} 7 \mathrm{a} 908 \mathrm{f} 16 \mathrm{ccbae} 6$. Doi: 10.1016/j.jviromet.2005.08.002.

SHIEH, M.T; SPEAR, P.G. Herpesvirus-induced cell fusion that is dependent on cell surface heparan sulfate or soluble heparin. Journal of Virology, v.68, n.2, p.1224-1228, 1994.

SUBRAMANIAN, G. et al. Defective entry of herpes simplex virus types 1 and 2 into porcine cells and lack of infection in infant pigs indicate species tropism. Journal of General Virology, v.76, p.2375-2379, 1995. Disponível em: http:/ /vir.sgmjournals.org/cgi/content/abstract/76/9/2375. Doi: 10.1099/0022-1317-76-9-2375. 